\title{
OPTIMISATION OF PECTIN EXTRACTION ASSISTED BY MICROWAVE FROM BANANA (Musa sapientum L.) FRUIT PEELS USING RESPONSE SURFACE METHODOLOGY
}

\author{
Anuthida Phaiphan ${ }^{1}$ \\ ${ }^{1}$ Department of Food Science and Technology, Faculty of Agriculture, Ubon Ratchathani Rajabhat University, \\ Ubon Ratchathani Province, Thailand, 34000 \\ *anuthida_p@hotmail.com
}

https://doi.org/10.34302/crpjfst/2019.11.2.10

\begin{tabular}{l} 
Article history: \\
Received: \\
$\quad 10$ May 2018 \\
Accepted: \\
10 April 2019 \\
\hline Keywords: \\
Banana fruit peel; \\
Microwave-assisted extraction \\
(MAE); \\
Musa sapientum, pectin \\
extraction; \\
Response surface \\
methodology.
\end{tabular}

\section{Article history:}

10 May 2018

10 April 2019

Keywords:

Banana fruit peel;

Microwave-assisted extraction

(MAE);

extraction;

methodology.

\begin{abstract}
In this study, microwave-assisted extraction (MAE) was used to extract pectin from waste banana (Musa sapientum L. CV. Kluai Namwa) fruit peels. Central composite design (CCD) was used to study and optimise the effects of processing parameters' variables (microwave irradiation, extraction time, and $\mathrm{pH}$ ) on the pectin yield, degree of esterification (DE), and galacturonic acid content (GA) of pectins extracted from dried banana fruit peels with hydrochloric acid of $0.05 \mathrm{M}$. Extraction parameters applied in this study are microwave irradiation (300-600 watt), extraction time (5-15 $\mathrm{min})$, and $\mathrm{pH}(1-3)$. The results showed that all the process variables had significant effect on the responses. The optimum conditions for the maximum pectin yield (13.47\%), DE (92.45\%), and GA $(87.99 \%)$ were obtained at microwave irradiation of 580 watt, extraction time of $15.86 \mathrm{~min}$, and $\mathrm{pH}$ of 1.71. Under the optimal conditions, close agreement between experimental and predicted values was obtained. From the results, second order polynomial model was developed and it adequately explained the data variation and significantly represented the actual relationship between independent variables and the response.
\end{abstract}

\section{Introduction}

Banana (Musa sapientum L. CV. Kluai Namwa) is one of the most important fruit crops that exists in large quantity in Thailand. Its fruits are used as snacks such as banana crisps or sweet banana crisps and their processed products include chips, puree, banana flour etc. that can be used to produce a variety of other products such as smoothies and nectars (Oliveira TÍ et al., 2016). Banana fruit peel is a by-product of the fruit industry and vendors; it is mostly used for fertilisation or as animal feed. However, proper utilisation of banana fruit peels can increase the economic value of the banana peels and reduce cost of waste disposal. Then, the use of banana fruit peels as a new raw material for the production of co-products in food industries such as pectin and other high value compounds such as cellulose nanofibres and phenolic compounds can be valued (Happi Emaga et al., 2008; Rebello et al., 2014). These are interesting propositions that not only can increase economic value, but also bring positive impact from the environmental perspective.

Pectin is a complex mixture of polysaccharides found in primary cell walls and middle lamella of plant tissues (Carpita and McCann, 2000). It consists of $\alpha$-D-galacturonic 
acid and some neutral sugars such as $\alpha$-Larabinose, $\alpha$-D-galactose, and $\alpha$-L-rhamnose (Basanta et al., 2012). The majority of pectin structure contains a backbone of $\alpha-(1,4)$-linked to $\alpha$-D-galacturonic acid units that are partially esterified with methyl alcohol or mineral acid at the carboxylic acid (Xu et al., 2014). The degree of esterification (DE) is defined as the percentage of carboxylic acid units in pectin esterified with methyl alcohol. The DE of the pectin is an important factor for the definition of properties of pectin (Seixas et al., 2014). Depending on DE, pectin is divided into two major groups, namely high methoxyl pectin (HMP) with DE value higher than 50\% and low methoxyl pectin (LMP) with DE value lower than 50\% (Yapo et al., 2007). The HMP forms gels when heated in solutions with a low $\mathrm{pH}$ (2-3.5) and at high concentrations of sugar (55-75\%), while the LMP can form gels in a wider $\mathrm{pH}$ range (2-6) without or with a little amount of sugar in the presence of divalent ions such as calcium (Wai et al., 2010). HMP and LMP have different physicochemical properties and thus different applications (Chan and Choo, 2013). In the food industry, pectin is widely used as food ingredient such as stabiliser, gelling agent, water binder, and thickener for the production of jellies, jams, fruit juices, and confectionery (Willats et al., 2006; Kratchanova et al., 2004). Among other uses, it has been used as a dietary fibre that has a positive effect on the digestive system and can reduce blood cholesterol. Moreover, LMP may be used as a gelling agent and texturising fat replacer to imitate the mouth-feel of lipids in low calorie food products for overweight and diabetic patients (May, 1990; Wai et al., 2010).

In the conventional extraction method, pectin is extracted using hot water (about $90^{\circ} \mathrm{C}$ ) acidified with mineral acids (Xu et al., 2014). However, this process is time-consuming, which normally takes at least three hours or even more than twenty hours to get sufficient amount of pectin and it leads to pectin degradation (Seixas et al., 2014; Liu et al., 2006). Therefore, there is a need to replace this extraction method with newer and better techniques to minimise the stated adverse effects. Microwave assisted extraction (MAE) is a non-conventional heating method that has been accepted as a powerful and potential alternative to conventional extraction methods, and it has many advantages such as higher extraction yield, shorter extraction time, less solvent extraction, and better quality products with lower capital cost (Maran et al., 2013b; Bagherian et al., 2011). Microwave is non-ionising radiation and it does not break down chemical bonds or cause molecular changes in the compounds by discharge of electrons. During extraction, microwave irradiation can directly extract plant constituents from sample solid matrixes and can induce the moisture inside the tissues to heat or evaporate, leading to tremendous increase in pressure on the cell walls. Finally, it breaks plant cell walls and releases the targeted compounds into the surrounding solvent (Dhobi et al., 2009). Over the last few years, MAE technique has been employed in pectin extraction from a variety of natural materials such as apple pomace, durian rind, pomelo peel, orange peel, and lime (Quoc et al., 2015; Fishman et al., 2006; Maran et al., 2013c)

From the extensive literature analysis, it has been found that many researchers have reported on pectin extraction from fruit peels. However, the optimal conditions for MAE technique of pectin extraction from banana fruit peel (Musa sapientum L. CV. Kluai Namwa) has not been reported yet. Hence, the purpose of this study is to develop a rapid MAE method for waste banana fruit peels as a new source of pectin and also to investigate and optimise the process parameters of MAE conditions such as microwave irradiation, $\mathrm{pH}$, and extraction time for maximum extraction yield and quality of extracted pectin by using three factors, threelevel central composite design. Response surface methodology (RSM) is designed to 
optimise the pectin extraction process. The optimised conditions determined from MAE technique in this study should provide important reference data for subsequent studies.

\section{Materials and methods}

\subsection{Materials}

Banana fruit peels were collected from a local vendor in Ubon Ratchathani province. The banana fruit peels were washed, cut into smaller pieces, and treated according to the method reported by Tangwongchai et al. (2006) with slight modifications in which ethanol was used instead of blanching in boiling water and drying temperature was changed to $65^{\circ} \mathrm{C}$. Briefly, the sample was treated with equal amount of $95 \%$ ethanol (1:1 solvent to fresh weight of sample ratio) at $80{ }^{\circ} \mathrm{C}$ for $10 \mathrm{~min}$. Then, the sample was washed with distilled water (3 times) and followed by drying of sample at $65{ }^{\circ} \mathrm{C}$ until weight of the sample was constant. The dried banana fruit peel (the moisture content of the sample was $3.88 \pm 0.04 \%$ in weight) was then ground into fine powder by a mechanical grinder and was passed through a pore size sieve ( 80 mesh) before kept in a dark airtight bottle at $-20 \pm 2{ }^{\circ} \mathrm{C}$ until further experimental analysis.

\subsection{Pectin extraction}

Microwave assisted extraction of banana fruit peels was performed according to the method reported by Li et al. (2012) with slight modifications. The dried peel powder was poured into $0.05 \mathrm{M}$ hydrochloric acid in a flask. The ratio of dried banana fruit peel to extracting solvent was 1:20 (w/v) and adjusted to the desired $\mathrm{pH}$ values $(1,2$, and 3 ) and thereafter stirred. The solution was then extracted with three powers of 300,450 , and 600 watt for three times $(5,10$, and $15 \mathrm{~min})$. After extraction, the mixture was filtrated using filter paper and centrifuged $(10000 \mathrm{~g})$ for $30 \mathrm{~min}$. Then, the supernatant was precipitated by adding $95 \%$ ethanol (the ratio of filtrate to ethanol was 1:2 $(\mathrm{v} / \mathrm{v}))$ and incubated at room temperature for 15 hours. After that, the coagulated pectin was filtered by using a Buchner funnel and was washed thrice by $95 \%$ ethanol and $95 \%$ acetone to remove the disaccharides and monosacharides (Minkov et al., 1996). In the next step, the wet pectin was dried at $60{ }^{\circ} \mathrm{C}$ in the hot air oven until a constant weight was obtained and was ground into powder. The pectin yield was calculated as follows:

$\%$ Extraction yield

$$
=\frac{\text { Weight of dried pectin (gram) }}{\text { Weight of dried powder sample (gram) }} \times 100
$$

\subsection{Determination of degree of esterification}

The degree of esterification (DE) of the banana fruit peel pectin was determined by the titrimetric method (USP 26 NF21, 2003) with minor modifications. Briefly, the dried pectin sample $(300 \mathrm{mg}$ ) was moistened with $2 \mathrm{~mL}$ of ethanol and dissolved in $100 \mathrm{~mL}$ of distilled water. The mixture was mixed until the sample was completely dissolved. Four drops of phenolphthalein indicator were added and the mixture was titrated with $0.5 \mathrm{M}$ sodium hydroxide $\left(\mathrm{V}_{1}\right)$. Thereafter, $10 \mathrm{~mL}$ of $0.5 \mathrm{M}$ sodium hydroxide was added and the mixture was stirred and kept for $15 \mathrm{~min}$. Then, $10 \mathrm{~mL}$ of $0.5 \mathrm{M}$ hydrochloric acid was added and the mixture was shaken until the pink colour disappeared. Finally, four drops of phenolphthalein indicator were added again and the mixture was titrated with $0.5 \mathrm{M}$ sodium hydroxide $\left(\mathrm{V}_{2}\right)$ until a pale pink colour that persisted after vigorous shaking was obtained. The DE value (\%) of the pectin sample was calculated as follows:

$\%$ Degree of esterification (DE) $=$ $\frac{\mathrm{NaOH}(\mathrm{V} 2)}{\mathrm{NaOH}(\mathrm{V} 1)+\mathrm{NaOH}(\mathrm{V} 2)} \times 100$

\subsection{Determination of galacturonic acid}

The galacturonic acid content was determined as described by Dedduang (2010) with some modifications. Briefly, dried pectin sample $(0.1 \mathrm{~g})$ was mixed and the volume was adjusted to $100 \mathrm{~mL}$ with $0.05 \mathrm{M}$ of ethanol. The 
mixture was stirred with a vortex and was incubated for $30 \mathrm{~min}$. Then, $10 \mathrm{~mL}$ of pectin solution was adjusted to $100 \mathrm{~mL}$ with distilled water in a volumetric flask. After that, $2 \mathrm{~mL}$ of diluted pectin solution was transferred to an Erlenmeyer flask. Then, $1 \mathrm{~mL}$ of $0.1 \%$ of cabazole and $12 \mathrm{~mL}$ of sulfuric acid concentration were added and the mixture was stirred for $25 \mathrm{~min}$ at room temperature. Then, the sample was measured for absorbance at $525 \mathrm{~nm}$. The galacturonic acid content was determined by comparison with a calibration curve obtained from standard galacturonic acid solutions (10-100 $\mu \mathrm{g} / \mathrm{mL})$.

\subsection{Experimental design}

A central composite design was used to the matrix of the experimental design to optimise and investigate the effect of independent variables (microwave radiation $\left(\mathrm{X}_{1}\right)$, extraction time $\left(\mathrm{X}_{2}\right), \mathrm{pH}\left(\mathrm{X}_{3}\right)$ on the three dependent variables; extraction yield, galacturonic acid content (GA), and degree of esterification (DE)). The independent variables and their coded and uncoded levels used in the central composite design are presented in Table 1.

Table 1. Independent variables and their levels used in the central composite design

\begin{tabular}{|l|c|c|c|c|c|c|}
\hline \multirow{2}{*}{ Independent variables } & \multirow{2}{*}{$\begin{array}{c}\text { Code } \\
\text { unit }\end{array}$} & $\boldsymbol{\alpha}$ & $\mathbf{- 1}$ & $\mathbf{0}$ & $\mathbf{1}$ & $\boldsymbol{\alpha}$ \\
\cline { 3 - 7 } & & $\mathbf{( - 1 . 6 8 2 )}$ & & & & $\mathbf{( + 1 . 6 8 2 )}$ \\
\hline Microwave radiation (watt) & $\mathrm{X}_{1}$ & 197.7 & 300 & 450 & 600 & 702.3 \\
Extraction time (min) & $\mathrm{X}_{2}$ & 1.59 & 5 & 10 & 15 & 18.41 \\
pH & $\mathrm{X}_{3}$ & 0.42 & 1 & 2 & 3 & 3.68 \\
\hline
\end{tabular}

All computations and three-dimensional surface plots in this study were carried out using the Minitab 16.1.1.0 (Minitab Inc., State College, PA, USA) software.

\subsection{Verification of model}

The optimum extraction conditions for microwave-assisted extraction, which depends on microwave irradiation, extraction time, and $\mathrm{pH}$, were obtained using RSM. The pectin yield, DE, and GA of banana fruit peels extracts were carried out under the optimum extraction conditions. The predicted and experimental values were compared to confirm the validity of the models by using two sample t-tests. The significantly different values at $95 \%$ confidence interval were analysed for each response.

\section{Results and discussion}

\subsection{Statistical analysis}

A central composite design or CCD is an experimental design to justify the relationship between independent and dependent variables. It is useful in response surface methodology for creating a second order or quadratic model for the dependent variable without using a complete three level factorial design (Choon-Hui et al., 2009). The experimental conditions of pectin extraction with hydrochloric acid and responses for the 20 pectin extraction treatments are shown in Table 2. A central composite design was used to investigate the effect of extraction time, microwave irradiation level, and $\mathrm{pH}$ on the pectin yield, DE, and GA of banana fruit peels. The results of the second order response surface models in the form of analysis of variance (ANOVA) for regression model are summarised 
in Table 3. The results showed that the $p$-values of the developed model for pectin yield, DE, and GA were $0.013,0.005$, and 0.002 , respectively, which indicated that the fitness of the model was highly significant $(p<0.05)$. The lack of fit tests showed insignificant results $(p$-value $=0.94$, $p$-value $=0.074$, and $p$-value $=0.19$ for pectin yield, DE, and GA, respectively), which indicated that the models could be used to predict the responses. The values of $R^{2}$ for yield, $\mathrm{DE}$, and GA were $0.81,0.85$, and 0.88 , respectively. This indicated that the models explained $81 \%, 85 \%$, and $88 \%$ of the total variation (Wai et al., 2010). The quadratic models for pectin yield, DE, and GA are shown in Table 4.

Table 2. Experimental conditions of pectin extraction with hydrochloric acid, and responses for the 20 pectin extraction treatments

\begin{tabular}{|c|c|c|c|c|c|c|}
\hline \multirow{2}{*}{ Runs } & \multicolumn{3}{|c|}{ Independent variables } & \multicolumn{3}{c|}{ Responses } \\
\cline { 2 - 7 } & Power & Time & $\mathrm{pH}$ & Yield & DE & GA \\
\hline 1 & $197.73(-1.68)$ & $10(0)$ & $2(0)$ & 6.98 & 70 & 50 \\
\hline 2 & $600(1)$ & $15(1)$ & $1(-1)$ & 13.27 & 85 & 88 \\
\hline 3 & $450(0)$ & $10(0)$ & $2(0)$ & 17.12 & 91 & 60 \\
\hline 4 & $702.27(1.68)$ & $10(0)$ & $2(0)$ & 11.58 & 80 & 75 \\
\hline 5 & $600(1)$ & $5(-1)$ & $3(1)$ & 9.38 & 61 & 27 \\
\hline 6 & $300(-1)$ & $15(1)$ & $1(-1)$ & 9.93 & 69 & 71 \\
\hline 7 & $450(0)$ & $18.41(1.68)$ & $2(0)$ & 13.44 & 80 & 80 \\
\hline 8 & $450(0)$ & $10(0)$ & $2(0)$ & 13.17 & 85 & 56 \\
\hline 9 & $450(0)$ & $10(0)$ & $3.68(1.68)$ & 9.49 & 75 & 32 \\
\hline 10 & $450(0)$ & $10(0)$ & $2(0)$ & 15.72 & 84 & 58 \\
\hline 11 & $600(1)$ & $15(1)$ & $3(1)$ & 10.39 & 96 & 58 \\
\hline 12 & $450(0)$ & $10(0)$ & $0.32(-1.68)$ & 8.03 & 75 & 68 \\
\hline 13 & $300(-1)$ & $15(1)$ & $3(1)$ & 15.68 & 80 & 43 \\
\hline 14 & $450(0)$ & $1.59(-1.68)$ & $2(0)$ & 6.6 & 70 & 26 \\
\hline 15 & $450(0)$ & $10(0)$ & $2(0)$ & 13.91 & 88 & 45 \\
\hline 16 & $450(0)$ & $10(0)$ & $2(0)$ & 14 & 90 & 46 \\
\hline 17 & $300(-1)$ & $5(-1)$ & $3(1)$ & 4.38 & 89 & 61 \\
\hline 18 & $450(0)$ & $10(0)$ & $2(0)$ & 22.24 & 84 & 48 \\
\hline 19 & $300(-1)$ & $5(-1)$ & $1(-1)$ & 5.82 & 72 & 48 \\
\hline 20 & $600(1)$ & $5(-1)$ & $1(-1)$ & 12.45 & 70 & 30 \\
\hline
\end{tabular}

Values in parentheses for independent variables are coded values according to the CCD design. Yield: pectin yield (\%); DE: degree of esterification (\%); GA: galacturonic acid content (\%) 
Phaiphan /Carpathian Journal of Food Science and Technology 2019,11(2), 127-140

Table 3. Analysis of variance (ANOVA) for regression model of pectin yield, degree of esterification (DE) and galacturonic acid (GA)

\begin{tabular}{|c|c|c|c|c|c|c|c|c|c|c|c|c|c|c|c|}
\hline \multirow{2}{*}{ Term } & \multicolumn{5}{|c|}{ Pectin Yield } & \multicolumn{5}{|l|}{ DE } & \multicolumn{5}{|l|}{ GA } \\
\hline & SS & DF & MS & F-value & p-value & SS & DF & MS & F-value & p-value & SS & DF & MS & F-value & p-value \\
\hline Model & 286.935 & 9 & 31.882 & 4.62 & 0.013 & 1352.98 & 9 & 150.331 & 6.09 & 0.005 & 5084 & 9 & 564.889 & 7.88 & 0.002 \\
\hline $\mathrm{X}_{1}$-Microwave radiation & 22.211 & 1 & 112.118 & 16.26 & 0.002 & 24.22 & 1 & 50.606 & 2.05 & 0.183 & 35.58 & 1 & 326.537 & 4.55 & 0.059 \\
\hline $\mathrm{X}_{2}$-Irradiation time & 60.496 & 1 & 58.54 & 8.49 & 0.015 & 208.24 & 1 & 29.45 & 1.19 & 0.3 & 2501.11 & 1 & 0.05 & 0 & 0.979 \\
\hline $\mathrm{X}_{3}-\mathrm{pH}$ & 0.049 & 1 & 45.58 & 6.61 & 0.028 & 65.77 & 1 & 184.169 & 7.47 & 0.021 & 862.71 & 1 & 151.652 & 2.12 & 0.177 \\
\hline $\mathrm{X}_{1} \mathrm{X}_{1}$ & 45.019 & 1 & 65.329 & 9.47 & 0.012 & 122.32 & 1 & 178.93 & 7.25 & 0.023 & 163.03 & 1 & 148.543 & 2.07 & 0.181 \\
\hline $\mathrm{X}_{2} \mathrm{X}_{2}$ & 39.043 & 1 & 50.26 & 7.29 & 0.022 & 146.61 & 1 & 178.93 & 7.25 & 0.023 & 0.01 & 1 & 0.317 & 0 & 0.948 \\
\hline$X_{3} X_{3}$ & 77.098 & 1 & 77.098 & 11.18 & 0.007 & 178.93 & 1 & 178.93 & 7.25 & 0.023 & 21.06 & 1 & 21.061 & 0.29 & 0.6 \\
\hline$X_{1} X_{2}$ & 23.052 & 1 & 23.052 & 3.34 & 0.097 & 492.82 & 1 & 492.823 & 19.98 & 0.001 & 882 & 1 & 882 & 12.3 & 0.006 \\
\hline $\mathrm{X}_{1} \mathrm{X}_{3}$ & 13.158 & 1 & 13.158 & 1.91 & 0.197 & 88.91 & 1 & 88.911 & 3.6 & 0.087 & 40.5 & 1 & 40.5 & 0.56 & 0.47 \\
\hline$X_{2} X_{3}$ & 6.808 & 1 & 6.808 & 0.99 & 0.344 & 25.17 & 1 & 25.17 & 1.02 & 0.336 & 578 & 1 & 578 & 8.06 & 0.018 \\
\hline Residual Error & 68.959 & 10 & 6.896 & & & 246.71 & 10 & 24.671 & & & 717 & 10 & 71.7 & & \\
\hline Lack-of-Fit & 12.316 & 5 & 2.463 & 0.22 & 0.94 & 198.21 & 5 & 39.641 & 4.09 & 0.074 & 500.16 & 5 & 100.033 & 2.31 & 0.19 \\
\hline Pure Error & 56.643 & 5 & 11.329 & & & 48.5 & 5 & 9.701 & & & 216.83 & 5 & 43.367 & & \\
\hline Cor Total & 355.894 & 19 & & & & 1599.69 & 19 & & & & 5801 & 19 & & & \\
\hline R-Squared & & & 0.81 & & & & & 0.85 & & & & & 0.88 & & \\
\hline Adj R-squared & & & 0.63 & & & & & 0.71 & & & & & 0.77 & & \\
\hline
\end{tabular}

SS = sum of squares; DF: degree of freedom; MS: mean square; Yield: pectin yield; DE: degree of esterification; GA: galacturonic acid content 
Table 4. Regression equations (for the coded variables) and statistical parameters of the models

\begin{tabular}{|l|c|c|}
\hline \multicolumn{1}{|c|}{ Equations } & \multicolumn{1}{|c|}{$\boldsymbol{F}$} & $\mathbf{R}^{2}$ \\
\hline $\begin{array}{l}\mathrm{EY}=-42.2412+0.1334 \mathrm{X}_{1}+2.5644 \mathrm{X}_{2}+11.3141 \mathrm{X}_{3}-0.0001 \mathrm{X}_{1}^{2}- \\
0.0747 \mathrm{X}_{2}^{2}-2.3130 \mathrm{X}_{3}^{3}-0.0023 \mathrm{X}_{1} \mathrm{X}_{2}-0.0085 \mathrm{X}_{1} \mathrm{X}_{3}+0.1845 \mathrm{X}_{2} \mathrm{X}_{3}\end{array}$ & $4.62(p=0.013)$ & 0.81 \\
\hline $\begin{array}{l}\mathrm{DE}=45.0156+0.0896 \mathrm{X}_{1}-1.8189 \mathrm{X}_{2}+22.7427 \mathrm{X}_{3}-0.0002 \mathrm{X}_{1}^{2}- \\
0.1409 \mathrm{X}_{2}^{2}-3.5236 \mathrm{X}_{3}^{2}+0.0105 \mathrm{X}_{1} \mathrm{X}_{2}-0.0222 \mathrm{X}_{1} \mathrm{X}_{3}+0.3547 \mathrm{X}_{2} \mathrm{X}_{3}\end{array}$ & $6.09(p=0.005)$ & 0.85 \\
\hline $\begin{array}{l}\mathrm{GA}=75.1882-0.2277 \mathrm{X}_{1}-0.0748 \mathrm{X}_{2}+20.6376 \mathrm{X}_{3}+0.0001 \mathrm{X}_{1}^{2}-0.0059 \mathrm{X}_{2}^{2}- \\
1.2089 \mathrm{X}_{3}^{2}+0.0140 \mathrm{X}_{1} \mathrm{X}_{2}-0.0150 \mathrm{X}_{1} \mathrm{X}_{3}-1.7 \mathrm{X}_{2} \mathrm{X}_{3}\end{array}$ & $7.88(p=0.002)$ & 0.88 \\
\hline
\end{tabular}

$\mathrm{EY}=$ extraction yield; DE: degree of esterification; GA: galacturonic acid content; $\mathrm{X}_{1}$ : microwave irradiation; $\mathrm{X}_{2}$ : time, $\mathrm{X}_{3}: \mathrm{pH}$

\subsection{The effect of extraction condition on pectin yield of banana fruit peels}

The pectin yield values of banana fruit peels ranged from $4.38 \%$ to $22.24 \%$ (w/w, based on dry weight of banana fruit peel) (Table 2), which depended on the extraction time, microwave irradiation, and $\mathrm{pH}$ (Figure 1(a-c)). The extraction time, microwave irradiation, and $\mathrm{pH}$ were important factors that affected on extraction efficiency in both linear and quadratic manners (Table 3). The results exhibited that the pectin yield increased with an increase in microwave irradiation from 400 to 600 watt (Figure 1(a, b)). The increase in microwave energy level can enhance the penetration of extracting agent into the pectin material matrix, deliver it to the materials efficiently through molecular interaction with the electromagnetic field, and offer a quick transfer of energy to the extraction solvent and matrix, allowing the components from the dissolution to be extracted (Gfrerer and Lankmayr, 2005; Yan et al., 2010). A longer extraction time shows a positive effect on the pectin yield (Figure 1(a, c)). It has been reported that a longer extraction time advocates the production of pectin yield ( $\mathrm{Li}$ et al., 2012; Bagherian et al., 2011). This might be due to the time requirement for the exposure of the banana fruit peel pectin to the release medium where the solvent penetrated into the samples, dissolved the banana fruit peel pectin, and subsequently diffused out from the raw solid samples (Maran, 2014; Samavati, 2013). However, an excessively long extraction time exposure in the microwave field can cause degradation of the pectin (Maran et al., 2013c; Xianzhe et al., 2011). Therefore, the pectin yield decreased when the extraction time was extended beyond 15 min. Moreover, $\mathrm{pH}$ is one of the independent variables that influences the pectin yield and it is necessary to choose a suitable $\mathrm{pH}$ to get the highest extraction of banana fruit peel pectin. It was exhibited that the pectin yield increased with increasing $\mathrm{pH}$ values, before it began to decline (Figure 1(b, c)). A higher amount of pectin yield could be obtained at $\mathrm{pH}$ values of 1.5-2. The extraction solvent with high concentration of acidity had the ability to fuse with the insoluble pectin and favored the hydrolysis of the insoluble pectin into soluble pectin, therefore, it could increase the pectin recovery from plant samples (Maran and Prakash, 2015; Maran et al., 2013a; El-Nawawi and Shehata, 1988; Ma et al., 2013) and reached its maximum. 
3.3. The effect of extraction condition on DE of banana fruit peel pectin
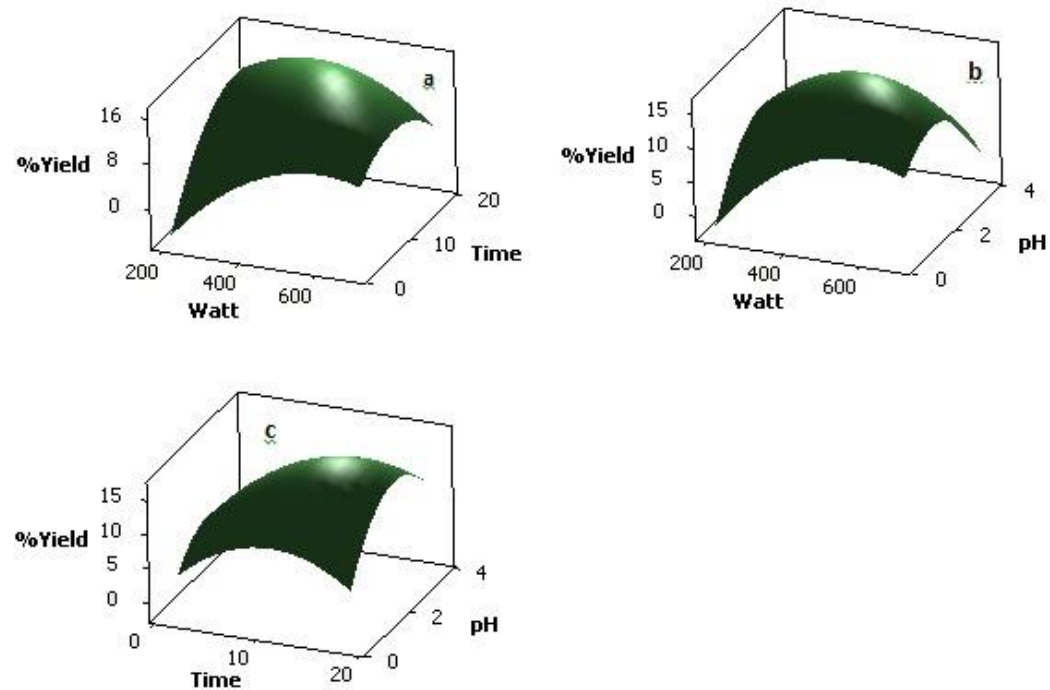

Figure 1. Response surface for effects of: (a) extraction time and microwave radiation level; (b) $\mathrm{pH}$ value and microwave radiation level; (c) $\mathrm{pH}$ value and extraction time on pectin yield from banana fruit peel.
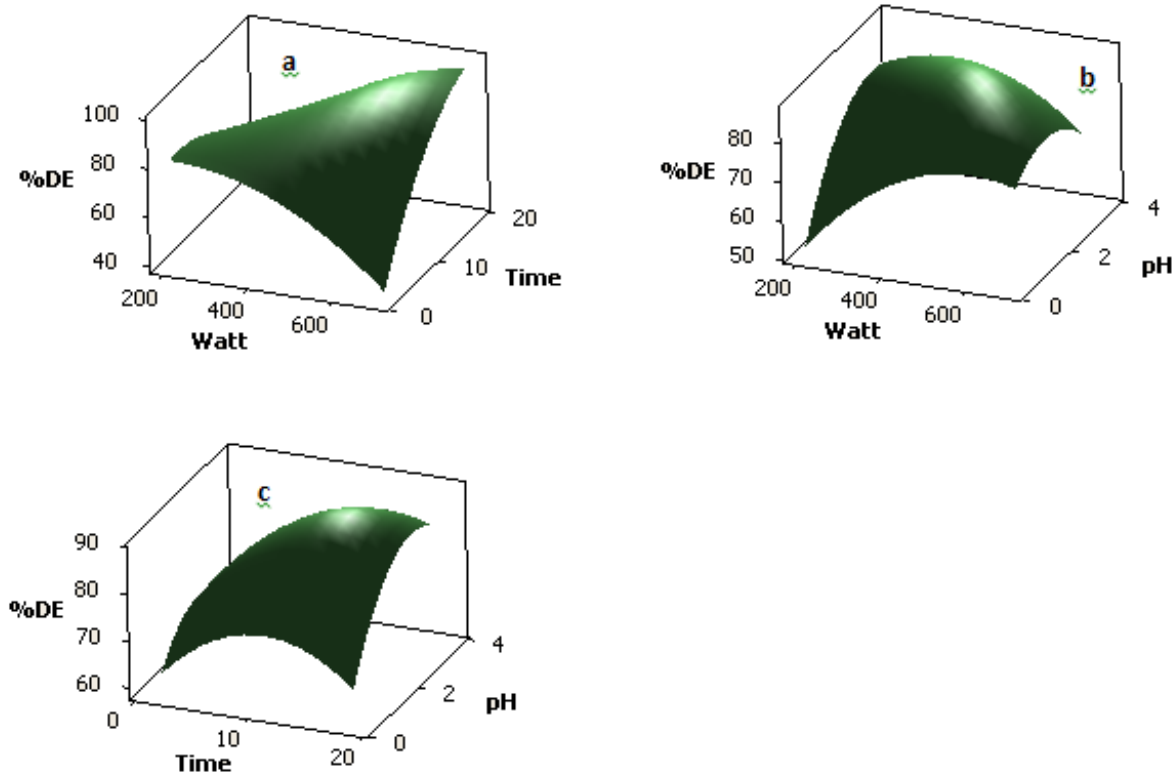

Figure 2. Response surface for effects of: (a) extraction time and microwave radiation level; (b) $\mathrm{pH}$ value and microwave radiation level; (c) $\mathrm{pH}$ value and extraction time on degree of esterification from banana fruit peel. 

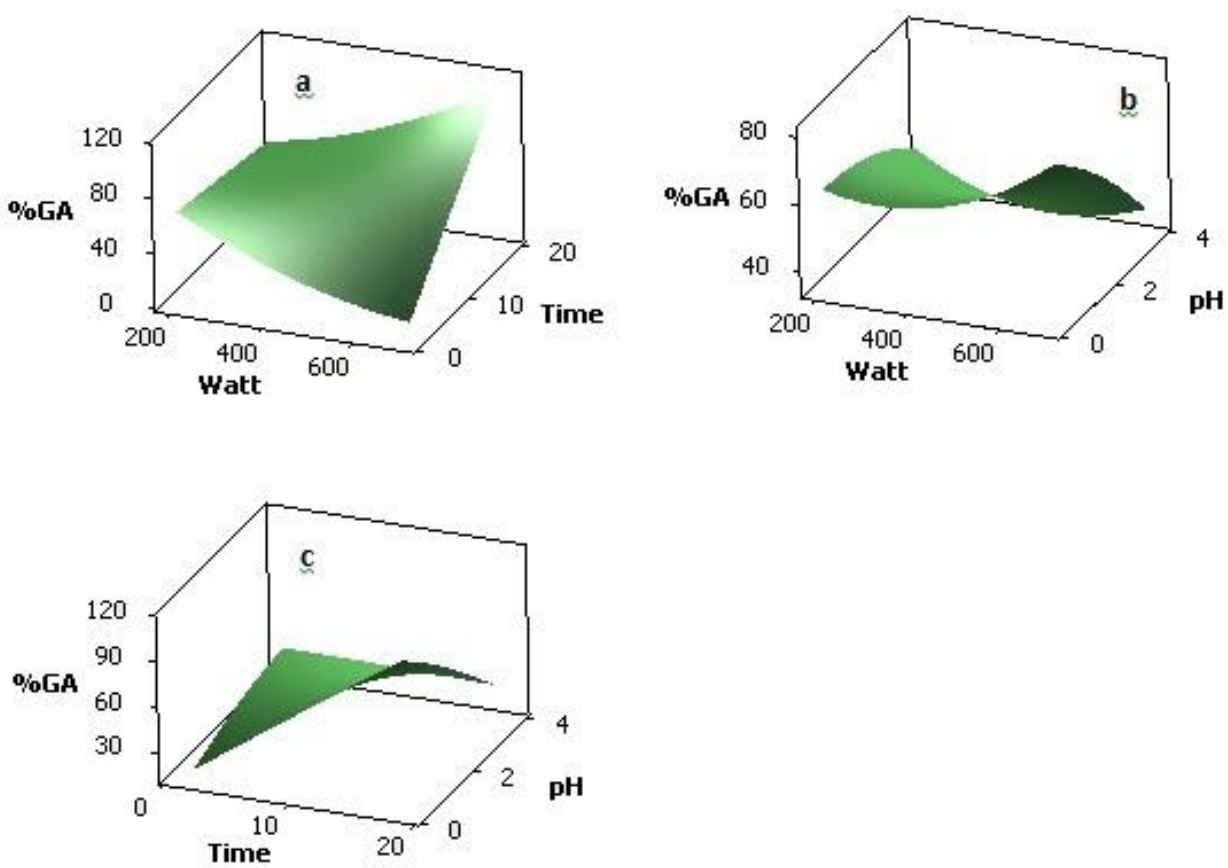

Figure 3. Response surface for effects of: (a) extraction time and microwave radiation level; (b) $\mathrm{pH}$ value and microwave radiation level; (c) $\mathrm{pH}$ value and extraction time on galacturonic acid from banana fruit peel.

The DE of banana fruit peel pectin ranged from $61 \%$ to $96 \%$ as presented in Table 2 . Based on the results, the banana fruit peel pectin extracted exhibited DE values higher than $50 \%$ and thus can be classified as HMP. The effects of the microwave irradiation, extraction time, and $\mathrm{pH}$ on the $\mathrm{DE}$ of the extracted pectin are shown in Figure 2(a-c). The results exhibited that extraction time and microwave irradiation had insignificant effect on the DE, but $\mathrm{pH}$ had significantly $(p<0.05)$ affected the DE in linear and quadratic manners. The interaction between microwave irradiation and extraction time showed a statistically significant $(p<0.05)$ effect on the DE (Table 3). The DE of the banana fruit peel pectin increased with the increase in microwave irradiation and $\mathrm{pH}$, before it began to decline. A higher amount of DE could be obtained at microwave irradiations of 450-550 watt, extraction time extended beyond $12 \mathrm{~min}$, and $\mathrm{pH}$ between 2 and 3 as presented in Figure 2(a-c). The DE values from $61 \%$ to $96 \%$ were obtained, a range higher than that earlier reported by Oliveira TÍ et al. (2016) and Happi Emaga et al. (2008) when extracting pectin from banana fruit peel with citric acid and sulfuric acid, respectively. It indicated that highly methylated pectin was isolated from the cell wall when extracting pectin from banana fruit peels with hydrochloric acid as solvent extraction. In general, pectin obtained under very severe extraction conditions (high microwave irradiation, long extraction time, and low $\mathrm{pH}$ ) have a high DE value because these severe conditions could increase DE of polygalacturonic chains (Wai et al., 2010).

\subsection{The effect of extraction condition on GA of banana fruit peel pectin}

The GA of banana fruit peel pectin ranged from $26 \%$ to $88 \%$ as presented in Table 2 . The effects of the microwave irradiation, extraction 
time, and $\mathrm{pH}$ on the GA of the extracted pectin are shown in Figure 3(a-c). The results exhibited that the extraction time, microwave irradiation, and $\mathrm{pH}$ had insignificant effect on the GA in linear and quadratic manners. The interaction between microwave irradiation and extraction time had significantly $(p<0.05)$ affected the GA and also the interaction between extraction time and $\mathrm{pH}$ (Table 3). The GA of the banana fruit peel pectin increased with the increase in microwave irradiation, before it began to decline. A higher amount of GA could be obtained at microwave irradiations of 500-600 watt and $\mathrm{pH}$ between 1 and 2 as presented in Figure 3(b). The GA increased with an increase in microwave irradiation of up to 500 watt and extraction time of up to $10 \mathrm{~min}$ as presented in Figure 3(a). The GA contents in the extracted pectin ranged from $26 \%$ to $88 \%$, similar to that reported by Oliveira TÍ et al. (2016) but higher than that reported by Happi Emaga et al. (2008). In this study, it has been exhibited that the GA contents were enhanced by increasing microwave irradiation and extraction time and decreasing $\mathrm{pH}$ values up to an inflection point of maximum GA content (about 702 watt, 18.41 min, $\mathrm{pH}$ 1.95), beyond which the GA values began to decline. This trend (the increasing GA value to a maximum point and followed by decreasing GA value) can be explained by the combination of two phenomena occurring during pectin extraction with low $\mathrm{pH}$ values at high microwave irradiation, which can remove sugars as a product of pectin hydrolysis (it contributes to GA values) and can cause their degradation by low $\mathrm{pH}$ values and high microwave irradiation heating (Garna et al., 2004).

\subsection{Optimisation of extraction parameters and validation of optimised condition}

The objective of optimisation was to ascertain the MAE conditions that give the maximum values for each dependent variable. The desirability function approach was applied in the optimisation process. This individual optimisation technique evaluates a point that maximises the desirability function (Maran et al., 2013a) as presented in Table 5. The results of individual numerical optimisation exhibited that microwave irradiation of 457 watt, $\mathrm{pH}$ of 2.12, and $12.8 \mathrm{~min}$ of extraction time can result in an optimum pectin yield of $16.62 \%$. The DE can result in maximum of $98.01 \%$ if the conditions of the MAE were set as $\mathrm{pH}$ of 1.95 , extraction time of $18.41 \mathrm{~min}$, and microwave irradiation of 702 watt. The optimum extraction condition of the MAE was $\mathrm{pH}$ of 1 , extraction time of $14.66 \mathrm{~min}$, and microwave irradiation of 450 watt, which can result in the maximum GA of $80 \%$.

Table 5. Predicted and experimental response values at optimum conditions of each responses using the equation models under these conditions of MAE

\begin{tabular}{|l|c|c|c|c|c|}
\hline \multirow{2}{*}{ Responses } & \multicolumn{2}{|c|}{ Optimum MAE condition } & \multicolumn{2}{c|}{ Maximum value } \\
\cline { 2 - 6 } & $\begin{array}{c}\text { Time } \\
(\mathbf{m i n})\end{array}$ & $\mathbf{p H}$ & $\begin{array}{c}\text { Irradiation } \\
\text { (watt) }\end{array}$ & Predicted & Experimental \\
\hline Extraction yield (\%) & 12.80 & 2.12 & 457.64 & 16.62 & $17.24 \pm 0.40$ \\
\hline Degree of esterification (\%) & 18.41 & 1.95 & 702.27 & 98.01 & $96.52 \pm 1.87$ \\
\hline Galacturonic acid content (\%) & 14.66 & 1 & 450 & 80 & $79.80 \pm 1.14$ \\
\hline
\end{tabular}

* Mean \pm standard deviation for 3 replication 
Table 6. Multiple response optimisation of overall optimum conditions (580 W, $15.86 \mathrm{~min}, \mathrm{pH} 1.71$ ) using MAE

\begin{tabular}{|l|c|c|}
\hline Responses & Predicted value & Experimental value* \\
\hline Extraction yield (\%) & 13.47 & $13.57 \pm 0.76$ \\
\hline Degree of esterification (\%) & 92.45 & $91.87 \pm 3.23$ \\
\hline Galacturonic acid content (\%) & 87.99 & $86.67 \pm 2.31$ \\
\hline
\end{tabular}

* Mean \pm standard deviation for 3 replication

A multiple numerical optimisation was carried out to find the optimum values of microwave irradiation, extraction time, and $\mathrm{pH}$ to the desired values for all responses. Several combinations of all the independent variables could give maximum pectin yield, DE, and GA. The multiple response optimisation using MAE showed that the overall optimum conditions were achieved at microwave irradiation of 580, extraction time of $15.86 \mathrm{~min}$, and $\mathrm{pH}$ of 1.71 (Table 6). Under these optimum conditions, the predicted response maximum value of pectin yield was $13.47 \%$, DE was $92.45 \%$, and GA was $87.99 \%$ (Table 6). The suitability of the optimised conditions for predicting the optimum response values was tested experimentally using the selected optimal conditions. Triplicate experiments were carried out under the optimised conditions and the mean values obtained from real experiments demonstrated the validation of the optimised conditions.

The pectin yield under the optimum conditions was $13.47 \%$, which was higher than the maximum yield of $2.18 \%$ obtained by Swamy and Muthukumarappan (2017) when extracting pectin from banana fruit peels by using continuous and intermittent microwave-assisted extractions. However, the conditions carried out by those researchers (Swamy and Muthukumarappan, 2017) were obtained with microwave irradiation of 900 watt, extraction time of 100 sec, and $\mathrm{pH}$ of 3.00 in the continuous method while in the intermittent process, they obtained the highest maximum yield of $2.58 \%$ at microwave irradiation of 900 watt, pulse ratio of 0.5 , and $\mathrm{pH}$ of 3.00 . On the contrary, the maximum pectin yield under the optimum conditions was $13.47 \%$, which was lower than the maximum pectin yield of 21.7\% reported by Happi Emaga et al. (2008) when extracting pectin from banana fruit peels with sulfuric acid by conventional solvent extraction method, and they obtained a high yield due to using harsher conditions (temperature $90{ }^{\circ} \mathrm{C}, \mathrm{pH} 1.5$, and time 240 min) than the optimum conditions of this study. Besides, the characteristics of the pectin yield of $21.7 \%$ reported by Happi Emaga et al. (2008b) had a degree of methylation and GA value of $49 \%$ and $40 \%$, respectively, which were lower than those obtained in this study under the optimum conditions.

\section{Conclusions}

In this study, pectin was successfully extracted from banana fruit peel and MAE was optimised for the extraction of pectin. Three independent variables at three levels of central composite design were used to optimise the experimental conditions. Pectin was successfully extracted from banana fruit peels with hydrochloric acid under different conditions of extraction time, microwave irradiation, and $\mathrm{pH}$. From the experimental results, microwave irradiation, extraction time, and $\mathrm{pH}$ were the most important variables that had affected on the responses. The optimal conditions were microwave 
irradiation of 580 watt, extraction time of $15.86 \mathrm{~min}$, and $\mathrm{pH}$ of 1.71 , with maximum pectin yield of $13.47 \%$, DE of $92.45 \%$, and GA of $87.99 \%$. Under the optimal conditions, the experimental values agreed with the predicted values. The optimised conditions determined from MAE technique in this study should provide important reference data for any subsequent study and the powdered pectin obtained can be produced with microwave-based extraction as a convenient pectin manufacturing process by the food industry.

\section{References}

Bagherian, H., Ashtiani, F.Z., Fouladitajar, A., et al. (2011). Comparisons between conventional, microwave and ultrasound assisted methods for extraction of pectin from grapefruit. Chemical Engineering and Processing: Process Intensification, 50(11), 1237-1243.

Basanta, M.F., Ponce, N.M.A., Rojas, A.M., et al. (2012). Effect of extraction time and temperature on the characteristics of loosely bound pectins from Japanese plum. Carbohydrate Polymers, 89(1), 230-235.

Carpita, N., McCann, M.C. (2000). The cell wall. In B. Buchanan (Ed.), Biochemistry and the molecular biology of plants. (pp. 52-108).

Chan, S., Choo, W. (2013). Effect of extraction conditions on the yield and chemical properties of pectin from cocoa husks. Food Chemistry, 141(4), 37523758.

Choon-Hui, T., Hasanah, M.G., Ainie, K., et al. (2009). Extraction and physicochemical properties of low free fatty acid crude palm oil. Food Chemistry, 113, 645-650.

Dedduang, O. (2010). Comparison of extracted pectin from three kinds of guava (Psidium guajava L.) to standard pectin. (Master's thesis, Graduated School), Srinakharinwirot University, Bangkok.

Dhobi, M., Mandal, V., Hemalatha, S. (2009). Optimization of microwave assisted extraction of bioactive flavonolignansilybinin. Journal of Chemical Metrology, 3(1), 13-23.

El-Nawawi, S.A., Shehata, F.R.F.R. (1988). Effect of the extraction temperature on the characteristics of pectin extracted from Egyptian orange peel. Biological Wastes, 24, 307-311.

Fishman, M.L., Chau, H.K., Hoagland, P.D., et al. (2006). Microwave-assisted extraction of lime pectin. Food Hydrocolloid, 20(8), 1170-1177.

Garna, H., Mabon, N., Wathelet, B., et al. (2004). New method for a two-step hydrolysis and chromatographic analysis of pectin neutral sugar chains. Journal of Agricultural and Food Chemistry, 52, 4652-4659.

Gfrerer, M., Lankmayr, E. (2005). Screening optimization and validation of microwave assisted extraction for the determination of persistent organochlorine pesticides. Analytica Chimica Acta, 533, 203-211.

Happi Emaga, T., Ronkart, S.N., Robert, C., et al. (2008). Characterisation of pectins extracted from banana peels (Musa AAA) under different conditions using an experimental design. Food Chemistry, 108, 463-471.

Kratchanova, M., Pavlova, E., Panchev, I. (2004). The effect of microwave heating of fresh orange peels on the fruit tissue and quality of extracted pectin. Carbohydrate Polymers, 56(2), 181-185.

Li, D., Jia, X., Wei, Z., et al. (2012). BoxBehnken experimental design for investigation of microwave-assisted extracted sugar beet pulp pectin. Carbohydrate Polymers, 88(1), 342-346. 
Liu, Y., Shi, J., Langrish, T.A.G. (2006). Water-based extraction of pectin from flavedo and albedo of orange peels. Chemical Engineering Journal, 120(3), 203-209.

Ma, S., Yu, S., Zheng, X., et al. (2013). Extraction, characterization and spontaneous emulsifying properties of pectin from sugar beet pulp. Carbohydrate Polymers, 98(1), 750-753.

Maran, J.P., Prakash, A. (2015). Process variables influence on microwave assisted extraction of pectin from waste Carcia papaya L. peel. International Journal of Biological Macromolecules, 73, 202-206.

Maran, J.P., Manikandan, S., Thirugnanasambandham, K., et al. (2013a). Box-Behnken design based statistical modeling for ultrasoundassisted extraction of corn silk polysaccharide. Carbohydrate Polymers, 92, 604-611.

Maran, J.P., Sivakumar, V., Thirgananasambandham, K., et al. (2013b). Degradation behavior of biocomposites based on cassava starch buried under indoor soil conditions. Carbohydrate Polymers, 101, 20-28.

Maran, J.P., Sivakumar, V., Thirugnanasambandham, K., et al. (2013c). Optimization of microwave assisted extraction of pectin from orange peel. Carbohydrate Polymers, 97(2), 703709.

Maran, J.P., Sivakumar, V., Thirugnanasambandham, K., et al. (2014). Microwave assisted extraction of pectin from waste Citrullus lanatus fruit rinds. Carbohydrate Polymers, 101, 786791.

May, C. (1990). Industrial pectins: Sources, production and applications. Carbohydrate Polymers, 12, 79-99.
Minkov, S., Minchev, A., Paev, K. (1996). Modeling of the hydrolysis and extraction of apple pectin. Journal of Food Engineering, 29(1), 107-113.

Oliveira, T.Í., Rosa M.F., Cavalcante, F.L., et al.(2016). Optimization of pectin extraction from banana peels with citric acid by using response surface methodology. Food Chemistry, 198, 113118.

Quoc, L.P.T., Huyen, V.T.N., Hue, L.T.N., et al. (2015). Extraction of pectin from pomelo (Citrus maxima) peels with the assistance of microwave and tartaric acid. International Food Research Journal, 22(4), 1637-1641.

Rebello, L.P.G., Ramos, A.M., Pertuzatti, P.B., et al. (2014). Flour of banana (Musa $A A A$ ) peel as a source of antioxidant phenolic compounds. Food Research International, 55, 397-403.

Samavati, V. (2013). Polysaccharide extraction from Abelmoschus esculentus: Optimization by response surface methodology. Carbohydrate Polymers, 95(1), 588-597.

Seixas, F.L., Fukuda, D.L., Turbiani, F.R.B., et al. (2014). Extraction of pectin from passion fruit peel (Passiflora edulis $\mathrm{f}$. flavicarpa) by microwave-induced heating. Food Hydrocolloids, 38, 186192.

Swamy, G.J., Muthukumarappan, K. (2017). Optimization of continuous and intermittent microwave extraction of pectin from banana peels. Food Chemistry, 220, 108-114.

Tangwongchai, R., Lerkchaiyaphum, K., Nantachai, K., et al. (2006). Pectin extraction from Citron peel (Citrus medica Linn.) and its use in food system Songklanakarin. Journal of Science and Technology, 28(6), 1351-1363. 
USP NF 21. 2003. The United States pharmacopeia-The national formulary. pp. 1401-1402. Rockville, MD: United States Pharmacopeial Convention.

Wai, W.W., Alkarkhi, A.F.M., Easa, A.M. (2010). Effect of extraction conditions on yield and degree of esterification of durian rind pectin: An experimental design. Food and Bioproducts Processing, 88(2), 209-214.

Willats, W.G.T., Knox, J.P., Mikkelsen, J.D. (2006). Pectin: New insights into an old polymer are starting to gel. Trends in Food Science \& Technology, 17(3), 97104.

Xianzhe, Z., Fangping, Y., Chenghai, L., et al. (2011). Effect of process parameters of microwave assisted extraction (MAE) on polysaccharides yield from Pumpkin. Journal of Northeast Agricultural University, 8(2), 79-86.

Xu, Y., Zhang, L., Bailina, Y., et al. (2014). Effects of ultrasound and/or heating on the extraction of pectin from grapefruit peel. Journal of Food Engineering, 126, 72-81.

Yan, M.M., Liu, W., Fu, Y.J., et al. (2010). Optimisation of the microwave-assisted extraction process for four main astragalosides in Radix Astragali. Food Chemistry, 119(4), 1663-1670.

Yapo, B.M., Robert, C., Etienne, I., et al. (2007). Effect of extraction conditions on the yield, purity and surface properties of sugar beet pulp pectin extracts. Food Chemistry, 100(4), 1356-1364.

\section{Acknowledgements}

This research project would like to thank Faculty of Agriculture, Ubon Ratchathani Rajabhat University (UBRU) for providing facilities. 